\title{
HACKMANITE/SODALITE FROM MYANMAR AND AFGHANISTAN
}

\author{
David Kondo and Donna Beaton
}

In recent years, significant amounts of gemquality sodalite/hackmanite-some unusually transparent-have been produced from the Mogok region of Myanmar and Badakhshan Province in Afghanistan. Samples from both countries varied in color, transparency, UV fluorescence/phosphorescence, tenebrescence, and UV-Vis-NIR spectra. The Burmese material was generally more included and showed weaker fluorescence and phosphorescence than the Afghan samples. EDXRF spectroscopy revealed traces of sulfur in all samples. The tenebrescence of many of the stones from both localities was strong enough for classification as hackmanite.

1 ackmanite $\left[\mathrm{Na}_{8} \mathrm{Al}_{6} \mathrm{Si}_{6} \mathrm{O}_{24}\left(\mathrm{Cl}_{2}, \mathrm{~S}\right)\right]$ is a sulfur-bearing variety of sodalite $\left[\mathrm{Na}_{8} \mathrm{Al}_{6} \mathrm{Si}_{6} \mathrm{O}_{24} \mathrm{Cl}_{2}\right]$ that gemologists typically distinguish according to its tenebrescence-that is, its ability to change color in response to the application or absence of certain wavelengths of light (e.g., white light or UV radiation; Japan Germany Gemmological Laboratory, 2008). Interestingly, a survey of the literature showed no

Editor's note: Consistent with its mission, GIA has a vital role in conducting research, characterizing gemstones, and gaining knowledge that leads to the determination of gemstone origins. The gemstones studied in this report are not subject to the Tom Lantos Block Burmese JADE Act of 2008, and their import was in accordance with U.S. law. See end of article for About the Authors and Acknowledgments.

Gems \& Gemology, Vol. 45, No. 1, pp. 38-43.

(c) 2009 Gemological Institute of America consistent definition for the term hackmanite. Some sources say it is sulfur-bearing sodalite that shows fluorescence (e.g., Jackson, 1997), possibly with the valence state of sulfur being a critical factor. Others stipulate tenebrescence as the defining criterion (e.g., Simpson and Weiner, 1989). Various sources indicate that hackmanite can either fade or deepen in color when left in darkness for days to months, depending on the origin of the material (e.g., Webster, 1994; Hainschwang, 2007; Tunzi and Pearson, 2008). In most cases, the material turns pink to purple/violet with exposure to ultraviolet radiation, and the color fades on exposure to sunlight or artificial "white" light sources. This behavior is reversible unless the stone is exposed to heat. Heating to more than $500^{\circ} \mathrm{C}$ destroys the UV sensitivity of hackmanite, leaving it in its bleached state (Medved, 1954; Kirk, 1955).

Hackmanite is usually found as translucent-toopaque crystalline aggregates, often intergrown with other minerals, especially nontenebrescent sodalite. Until recently, examples of transparent faceted hackmanite were reported only rarely (see, e.g., Koivula and Kammerling, 1989a,b). Hackmanite is known from Canada (Mont Saint-Hilaire, Quebec; and Bancroft, Ontario); Magnet Cove, Arkansas; Libertyville, New Jersey; Minas Gerais, Brazil; the Kola Peninsula, Russia; and Greenland (Miser and Glass, 1941; Webster, 1994; Bernard and Hyrŝl, 2004). More recently, it was reported from the Mogok area of Myanmar and the Badakhshan Province of Afghanistan (e.g., Johnson and Koivula, 1998; Moore, 2001, 2002; Liu et al., 2004; Japan Germany Gemmological Laboratory, 2008; Tunzi and Pearson, 2008).

In April 2007, gem dealer Hussain Rezayee informed the authors about additional production of hackmanite/sodalite from Myanmar, in an area $11 \mathrm{~km}$ east of Mogok at Pyang Gyi, near Pein Pyit. Production 


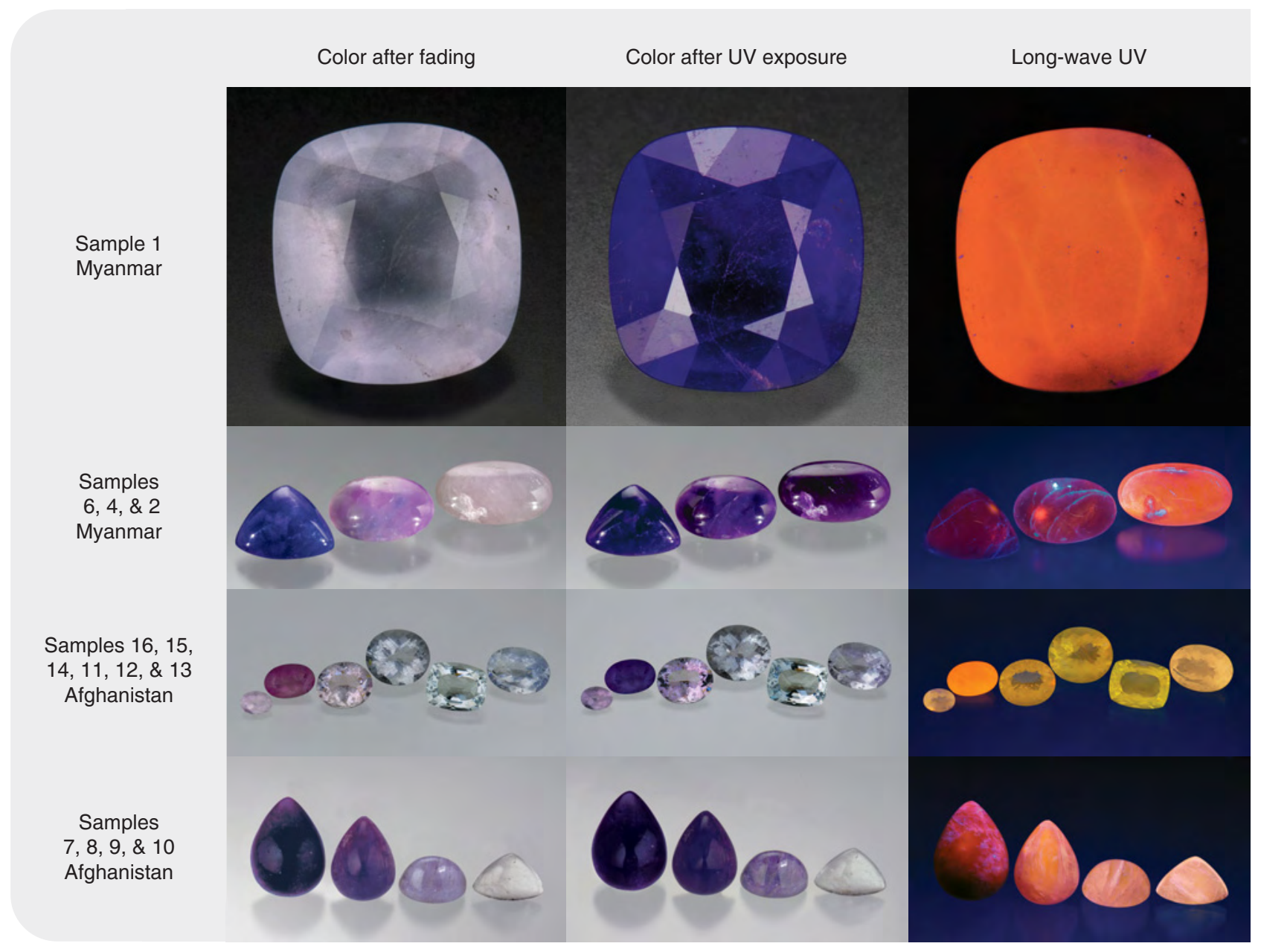

Figure 1. These samples of Burmese and Afghan hackmanite/sodalite, which were studied for this report, are shown in their desaturated color state, after exposure to short-wave UV radiation, and during exposure to longwave UV. See table 1 for sample weights. Photos by Robert Weldon.

started in mid-2003, but originally was of low quality. Beginning in 2007, about 2,000 carats per month of various sizes were being cut into cabochons and faceted stones, according to Mr. Rezayee. He loaned several of the Burmese cabochons to us for examination, and Bangkok-based gem dealer G. Scott Davies donated a faceted Burmese hackmanite to GIA.

Mr. Rezayee also loaned us samples of hackmanite/sodalite that were produced in Badakhshan since 2002. These samples generally appeared similar to the material from Myanmar, though some were unusually transparent, and Mr. Rezayee reported that clean stones up to $18 \mathrm{ct}$ have been faceted from the Afghan material. He has cut approximately 1,000 carats of faceted stones and 10,000 carats of cabochons (ranging up to $40 \mathrm{ct}$ ) of the Afghan hackmanite/sodalite.

Rough material from both localities is commonly oiled to enhance its transparency. According to Mr.
Davies and F. Hashmi (pers. comm., 2008), some is oiled after being cut and polished; since any recutting will cause the cracks to reappear, such stones are re-oiled to improve their apparent clarity.

\section{MATERIALS AND METHODS}

Six samples from Myanmar (a 0.64 ct cushion cut and five cabochons weighing 20.23-56.20 ct) and 10 from Afghanistan (six faceted stones weighing $0.44-4.83 \mathrm{ct}$ and four cabochons of 5.92-29.94 ct) represented as hackmanite were examined for this study (e.g., figure 1). We evaluated all samples for color in a Gretag Macbeth Judge II light box, using a D65 daylight-equivalent fluorescent lamp. To assess tenebrescence, we examined the stones after they were faded by exposure to a standard 100-watt household incandescent bulb or a 4.5-watt daylight-equivalent fluorescent lamp, and immediately after their 
color was intensified by exposure to short-wave UV radiation (using a 4-watt bulb). Generally it was necessary to expose the samples to white light for a period of several hours to more than one day to attain the maximum amount of fading, whereas only several minutes were needed to deepen the color with the short-wave UV lamp. We also examined the color (starting in both color states) of the most tenebrescent samples (nos. 1, 2, 4, and 15) after they were held in the dark for at least three weeks.

Refractive indices were measured with a standard refractometer, and specific gravity was determined hydrostatically. We examined all samples with a gemological microscope using various lighting techniques (darkfield, diffused light, reflected light, fiberoptic illumination, etc.). We observed fluorescence and phosphorescence in a darkened room using a standard long- and short-wave UV lamp. All samples were characterized with Raman, Fourier-transform infrared (FTIR), and energy-dispersive X-ray fluorescence (EDXRF) spectroscopy. For comparison, we also characterized three transparent blue sodalites of unknown locality from the reference collection at the GIA Laboratory in New York by FTIR and EDXRF spectroscopy. UV-visible-near infrared (UVVis-NIR) spectroscopy was performed on 15 Burmese and Afghan samples that showed sufficient diaphaneity using a double-beam spectrophotometer scanning from 900 to $200 \mathrm{~nm}$; spectra were acquired for 13 of these samples in both their faded and UVexcited color states.

\section{RESULTS AND DISCUSSION}

Standard gemological properties and tenebrescence of all the Burmese and Afghan hackmanites/sodalites

TABLE 1. Properties, including tenebrescence, of 16 hackmanite/sodalite samples from Myanmar and Afghanistan. ${ }^{a}$

\begin{tabular}{|c|c|c|c|c|c|c|c|c|c|c|}
\hline Source & Sample & Cut & Diaphaneity & $\begin{array}{l}\text { Weight } \\
\text { (ct) }\end{array}$ & $\mathrm{Rl}$ & $S G$ & $\begin{array}{l}\text { Color after fading } \\
\text { (white light) }\end{array}$ & $\begin{array}{l}\text { Color after UV } \\
\text { exposure }\end{array}$ & Tenebrescence & Name \\
\hline \multirow[t]{6}{*}{ Myanmar } & 1 & Faceted cushion & Transparent & 0.64 & 1.479 & 2.26 & Light grayish violet & Medium violet & Strong & Hackmanite \\
\hline & 2 & Oval cabochon & Translucent & 24.83 & 1.47 & 2.29 & Very light purple & $\begin{array}{l}\text { Medium-to-dark } \\
\text { purple }\end{array}$ & Strong & Hackmanite \\
\hline & 3 & Oval cabochon & $\begin{array}{l}\text { Translucent to } \\
\text { semi-opaque }\end{array}$ & 56.20 & 1.47 & 2.29 & $\begin{array}{l}\text { Blue unchanged; } \\
\text { purple got paler and } \\
\text { more violet }\end{array}$ & $\begin{array}{l}\text { Medium-to-dark } \\
\text { purple ranging to } \\
\text { blue }\end{array}$ & Weak & Hackmanite \\
\hline & 4 & Oval cabochon & $\begin{array}{l}\text { Translucent to } \\
\text { semi-opaque }\end{array}$ & 20.23 & 1.47 & 2.44 & $\begin{array}{l}\text { Light-to-medium } \\
\text { pinkish purple; near- } \\
\text { colorless areas } \\
\text { unchanged }\end{array}$ & $\begin{array}{l}\text { Medium purple and } \\
\text { near colorless }\end{array}$ & Strong & Hackmanite \\
\hline & 5 & $\begin{array}{l}\text { Marquise } \\
\text { cabochon }\end{array}$ & Translucent & 23.77 & 1.47 & 2.29 & $\begin{array}{l}\text { Medium purple with } \\
\text { violet }\end{array}$ & $\begin{array}{l}\text { Dark purple to } \\
\text { violet }\end{array}$ & Weak & Hackmanite \\
\hline & 6 & $\begin{array}{l}\text { Triangular } \\
\text { cabochon }\end{array}$ & Translucent & 22.26 & 1.47 & 2.30 & Medium violet & Dark violet & Moderate & Hackmanite \\
\hline \multirow[t]{10}{*}{ Afghanistan } & 7 & Pear cabochon & Semi-opaque & 29.94 & 1.45 & 2.28 & $\begin{array}{l}\text { Medium purple with } \\
\text { very dark purple area }\end{array}$ & Dark purple & Very weak & Sodalite \\
\hline & 8 & Pear cabochon & Translucent & 16.97 & 1.45 & 2.30 & Light purple & Medium purple & Weak & Hackmanite \\
\hline & 9 & Oval cabochon & Translucent & 12.39 & 1.45 & 2.30 & Light violet & Medium violet & Weak & Hackmanite \\
\hline & 10 & $\begin{array}{l}\text { Triangular } \\
\text { cabochon }\end{array}$ & Transparent & 5.92 & 1.46 & 2.30 & Near colorless & Very light violet & Very weak & Sodalite \\
\hline & 11 & Faceted oval & Transparent & 4.83 & 1.480 & 2.31 & Very light blue & Very light blue & None & Sodalite \\
\hline & 12 & Faceted cushion & Transparent & 4.25 & 1.480 & 2.31 & $\begin{array}{l}\text { Very light grayish } \\
\text { greenish blue }\end{array}$ & $\begin{array}{l}\text { Very light grayish } \\
\text { greenish blue }\end{array}$ & Very weak & Sodalite \\
\hline & 13 & Faceted oval & Transparent & 3.34 & 1.480 & 2.31 & $\begin{array}{l}\text { Very light violetish } \\
\text { blue }\end{array}$ & Light bluish violet & Moderate & Hackmanite \\
\hline & 14 & Faceted oval & Transparent & 2.59 & 1.480 & 2.31 & Very light violet & Light violet & Moderate & Hackmanite \\
\hline & 15 & Faceted oval & Transparent & 1.45 & 1.480 & 2.31 & $\begin{array}{l}\text { Medium pinkish } \\
\text { purple }\end{array}$ & $\begin{array}{l}\text { Medium-intense } \\
\text { purple }\end{array}$ & Strong & Hackmanite \\
\hline & 16 & Faceted oval & Transparent & 0.44 & 1.480 & 2.31 & Very light pink & Light purple & Moderate & Hackmanite \\
\hline
\end{tabular}

${ }^{2}$ The color states described above were assessed after fading with a 100-watt incandescent light for several hours or longer at a distance of approximately $15 \mathrm{~cm}$ (6 in.), and after inducing color with several minutes of exposure to a standard short-wave UV lamp. 

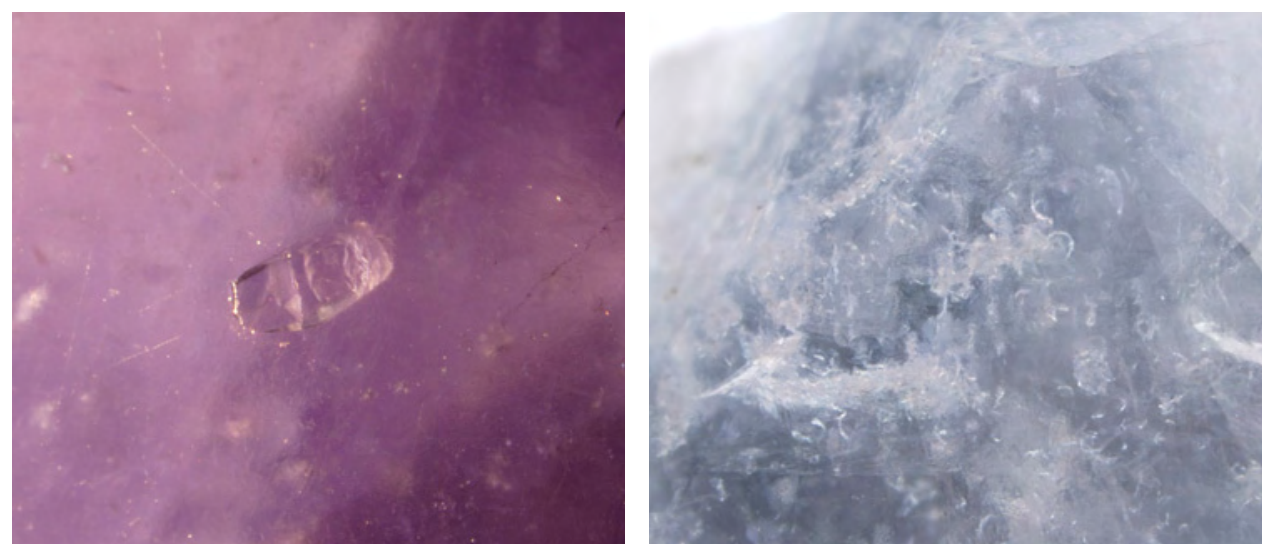

Figure 2. Crystalline inclusions were present in some of the Burmese samples of hackmanite/sodalite studied (left-sample 4, rightsample 1). Photomicrographs by $D$. Kondo; fields of view $\sim 4.8$ and $3.3 \mathrm{~mm}$, respectively.

are summarized in table 1. Exposure to short-wave UV for several minutes perceptibly changed the color of 15 of the 16 stones: Eight showed strong-to-moderate tenebrescence, four showed a weak change, and four had a very weak or no change. For the purposes of this study, we defined samples with weak to strong tenebrescence as hackmanite, and samples with no or very weak tenebrescence as sodalite. The tenebrescent effect can be seen in figure 1, which shows samples in their faded, UV-excited, and fluorescent states. The stones showed a much faster reaction to UV radiation and to white light than from being kept in the dark. The daylight-equivalent fluorescent lamp induced fading as rapidly and effectively as the incandescent bulb.

Since these samples were obviously sensitive to some wavelengths of radiation, we carefully examined their condition before and after all spectroscopy, as the various lasers (514 and $830 \mathrm{~nm}$ ), Xrays, and $\mathrm{UV}$, visible, and infrared wavelengths used in the equipment might affect the color state. We found that no perceptible changes in color occurred during the testing process, although Hainschwang (2007) noted a fading of the color of Burmese hackmanite after exposure to a green laser $(514 \mathrm{~nm})$ for two minutes.

Samples 1, 2, and 4 (from Myanmar) and 15 (from Afghanistan) generally showed a rapid and distinct change from light purple or violet to medium-dark purple or violet within a few seconds of exposure to UV radiation. Several Afghan samples showed moderate tenebrescence by deepening to a medium purple or violet. Burmese sample 4 had an uneven change of color: A broad white patch across part of the stone (not visible in figure 1) showed no change, although areas at the stone's periphery had strong tenebrescence. The area that did not change color was identified as nepheline by Raman analysis. The significant nepheline component of this stone explains its abnormally high SG (2.44) compared to the published range for sodalite/hackmanite (2.15-2.35; for nepheline, the values are 2.55-2.65 according to Webster, 1994).

The four samples that were kept in the dark for at least three weeks showed no change in color from their faded state (induced by exposure to the incandescent bulb for one day), with one exception: Sample 15 became slightly less saturated, indicating that our starting color state had not been completely faded. After the color of these samples was deepened by exposure to short-wave UV radiation for several minutes, storage in the dark for at least three weeks caused their color to become slightly less saturated.

For all stones except sample 4, the physical properties were consistent with published values for sodalite and hackmanite (see Webster, 1994; Johnson and Koivula, 1998). In general, the Burmese samples showed fractures, irregular white masses, and inclusions of transparent crystals (e.g., figure 2). Raman analysis identified the transparent crystals as pyroxene in sample 3 and mica in sample 5, but we were unable to identify the transparent crystals in other stones. The Afghan samples examined for this study were for the most part much less saturated, less included, and more transparent than the Burmese material. They often contained "fingerprints" (figure 3 , left), transparent to whitish included crystals (figure 3, center), wispy cross-hatched inclusions (figure 3 , right), and fractures containing a whitish foreign material.

Both a whitish appearance in Afghan samples and fluorescence seen in fractures in Burmese stones suggested clarity enhancement. This was confirmed in all eight of the Afghan stones by the presence of absorption bands between 3050 and $2830 \mathrm{~cm}^{-1}$ and at $\sim 3412 \mathrm{~cm}^{-1}$ in the FTIR spectra. The $0.64 \mathrm{ct}$ faceted Burmese sample did not show any visual or 

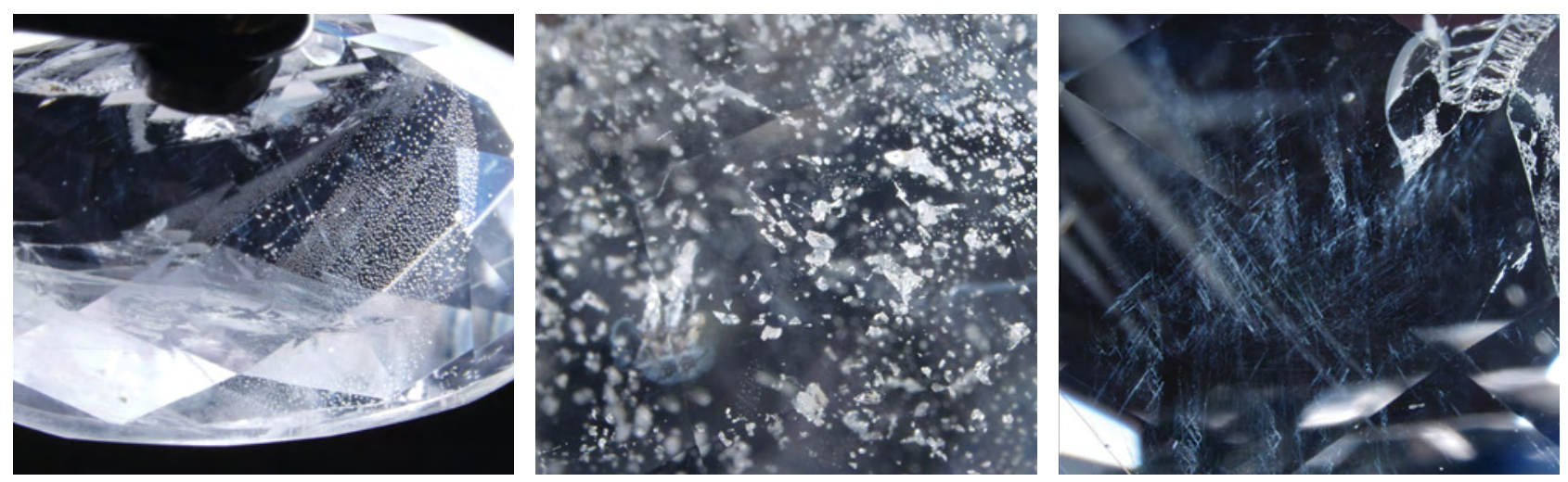

Figure 3. These images show some typical internal features observed in Afghan hackmanite/sodalite, including a large fingerprint (left; sample 13), numerous transparent crystals (center; sample 11), and some wispy crosshatched clouds (right; sample 12). Fields of view are approximately $6.8 \mathrm{~mm}, 3.1 \mathrm{~mm}$ and $4.9 \mathrm{~mm}$, respectively. Photomicrographs by D. Kondo.

spectral evidence of clarity enhancement, while the four Burmese cabochon samples tested had saturated absorption in the region of interest, so no conclusions could be drawn.

All the samples fluoresced to long-wave UV radiation. The Afghan stones generally gave a strong yellow to orange reaction, and most of the Burmese material fluoresced weak orange (samples 1 and 2 showed a moderate-to-strong orange). When exposed to short-wave UV, the Afghan samples fluoresced a weak-to-moderate red or orange that was quickly obscured by a stronger moderate-to-strong white to yellowish white fluorescence, whereas the Burmese material showed strong greenish yellow fluorescence to short-wave UV in fissures; the Burmese host material itself did not react to short-wave UV, except for sample 1, which had a weak red reaction and lacked fissures.

Phosphorescence to UV radiation was also present in varying amounts. After exposure to short-wave UV, the Afghan material showed a moderate-tostrong yellowish white phosphorescence lasting for several minutes; the long-wave reaction had weaker intensity but similar duration. Burmese samples 1 and 2 showed very weak to weak white phosphorescence to short-wave UV that lasted for perhaps one minute. Similar phosphorescent reactions for Burmese and Afghan samples were described by Tunzi and Pearson (2008).

As expected, the Raman spectra of all the samples were indistinguishable from the spectrum of sodalite. In the mid-infrared region, the FTIR spectra showed some differences, most notably between 2750 and $2250 \mathrm{~cm}^{-1}$. In addition, the sodalite reference samples showed absorption peaks in the infrared spectrum at 4874, 4690, 4110, 3971, 3033,
2655 , and $2272 \mathrm{~cm}^{-1}$ that were not seen in any of the samples submitted for this study. Qualitative chemical analysis by EDXRF spectroscopy of all the Burmese and Afghan samples showed a weak sulfur peak, which the sodalite references lacked.

In the literature, tenebrescence and fluorescence of hackmanite are generally attributed to $\mathrm{S}^{2-}$ (e.g., Liu et al., 2004; Sidike et al., 2007; Japan Germany

Figure 4. These UV-Vis-NIR spectra for representative hackmanites from Myanmar and Afghanistan show an increase in absorption at $550 \mathrm{~nm}$ for the UVexcited state (in blue) compared to the desaturated color state (in red). These samples were run with the beam entering the table and exiting the culet. Path lengths for the $0.64 \mathrm{ct}$ Burmese and the $2.59 \mathrm{ct}$ Afghan samples are $\sim 3.45$ and $5.60 \mathrm{~mm}$, respectively.

\section{UV-VIS-NIR ABSORPTION SPECTRA}

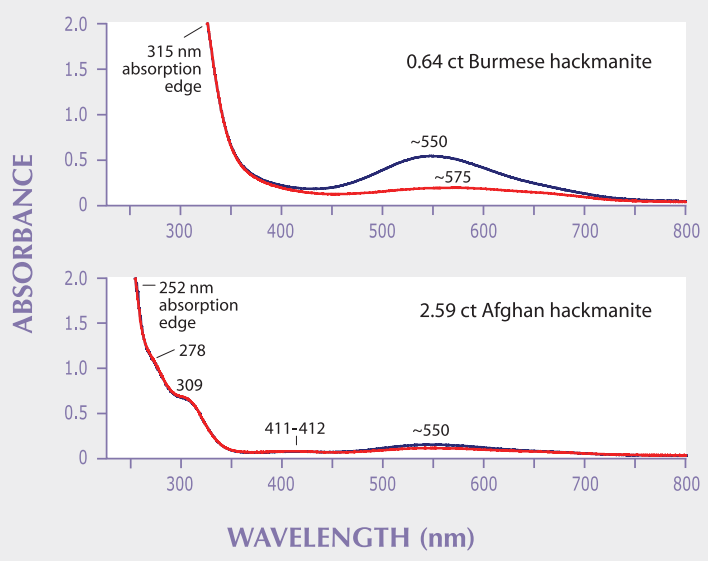


Gemmological Laboratory, 2008). To better understand the absorption features that lead to the perceived color, figure 4 provides UV-Vis-NIR absorption spectra of representative Burmese and Afghan hackmanites (showing both strong and weak tenebrescence) in their desaturated and UV-excited color states. In general, all the spectra had a broad band in the mid-500 $\mathrm{nm}$ range, although in some cases the band peaked closer to $590 \mathrm{~nm}$. The lesstransparent Burmese samples (all six tested) only showed this $\sim 550 \mathrm{~nm}$ band and an absorption edge ranging from $\sim 310$ to $350 \mathrm{~nm}$. The Afghan samples (eight out of 10 tested) showed this mid-500 nm feature plus other bands in many cases. For example, a minor band in the 410-412 $\mathrm{nm}$ range was present in six of the Afghan samples, but not in any of the Burmese samples. We also saw peaks with typical positions of 277 and $313 \mathrm{~nm}$ in Afghan samples; however, we cannot say if these bands are present in the Burmese samples as well since this region was saturated in those spectra.

For tenebrescent samples, the band in the mid$500 \mathrm{~nm}$ region grew in absorption after the stone was excited with UV radiation: This is the band responsible for the color and phenomenon. Many samples in the desaturated color state showed weak peaks superimposed on the main band, with the most prominent secondary band centered at $672 \mathrm{~nm}$. Similar results were recorded by Hainschwang (2007).

\section{REFERENCES}

Bernard J.H., Hyršl J. (2004) Minerals and their Localities. Granit, Prague, Czech Republic.

Hainschwang T. (2007) A study of an unusual hackmanite from Myanmar. www.gemlab.net/website/gemlab/index.php?id=187, posted November 30.

Jackson J. (1997) Glossary of Geology, 4th ed. American Geological Institute, Alexandria, VA, p. 288.

Japan Germany Gemmological Laboratory (2008) Strange jewel "hackmanite." Gem Information, Vol. 37-38, July 23, pp. 26-32 (in Japanese).

Johnson M.L., Koivula J.I., Eds. (1998) Gem News: Hackmanite from Myanmar. $G \uplus G$, Vol. 34, No. 3, pp. 223-224.

Kirk R.D. (1955) The luminescence and tenebrescence of natural and synthetic sodalite. American Mineralogist, Vol. 40, No. 22 , pp. 22-31.

Koivula J.I., Kammerling R.C., Eds. (1989a) Gem News: Hackmanite-a remarkable variety of sodalite. $G \uplus G$, Vol. 25, No. 2, pp. 112-113.

Koivula J.I., Kammerling R.C., Eds. (1989b) Gem News: Update on hackmanite. $G \uplus G$, Vol. 25, No. 4, pp. 245-246.

Liu S.I., Peng M.S., Tse E.Y.L. (2004) The tenebrescence of hackmanite from Afghanistan. Journal of the Gemmological

\section{CONCLUSION}

Clearly, many of the Burmese and about half the Afghan samples examined in this study showed the distinct tenebrescence that is characteristic for hackmanite. However, a few saturated blue-to-purple Burmese stones and some very desaturated Afghan stones showed little or no change in color with exposure to UV radiation or bright white light sources, or to placement in the dark for extended periods. Stones with no or very weak tenebrescence may best be referred to as sodalite, despite containing traces of sulfur. Although hackmanite is commonly described in the gemological literature as a sulfur-bearing variety of sodalite that is distinguished by its tenebrescence, there are no guidelines clearly separating hackmanite from sodalite. We suggest that only sodalite with noticeable tenebrescence be called hackmanite.

\section{ABOUT THE AUTHORS}

Mr.Kondo (david.kondo@gia.edu) is gemological research associate, and Ms. Beaton is manager of Identification Services, at the GIA Laboratory in New York.

\section{ACKNOWLEDGMENTS}

The authors thank Hussain Rezayee (Pearl Gem Co., Beverly Hills, California) and G. Scott Davies (AmericanThai Trading, Bangkok) for supplying information and samples for this report. Farooq Hashmi (Intimate Gems, Jamaica, New York) is thanked for helpful discussions.
Association of Hong Kong, Vol. 25, pp. 85-90.

Medved D.B. (1954) Hackmanite and its tenebrescent properties. American Mineralogist, Vol. 39, pp. 617-629.

Miser H.D., Glass J.J. (1941) Fluorescent sodalite and hackmanite from Magnet Cove, Arkansas. American Mineralogist, Vol. 26, pp. 437-445.

Moore T. (2001) What's new in minerals-Tucson show 2001. Mineralogical Record, Vol. 32, No. 3, pp. 245-257.

Moore T. (2002) What's new in minerals-Denver show 2001. Mineralogical Record, Vol. 33, No. 1, pp. 83-99.

Sidike A., Sawuti A., Wang X.-M., Zhu H.-J., Kobayashi S., Kusachi I., Yamashita N. (2007) Fine structure in photoluminescence spectrum of $\mathrm{S}^{2-}$ center in sodalite. Physics and Chemistry of Minerals, Vol. 34, pp. 477-484.

Simpson J.A., Weiner E.S.C. (1989) The Oxford English Dictionary, 2nd ed., Vol. VI. Clarendon Press, Oxford, pp. 1001-1002.

Tunzi J., Pearson G. (2008) Hackmanite, tugtupite and afghanite-Tenebrescence and fluorescence of some sodalite related minerals. Australian Gemmologist, Vol. 23, No. 8, pp. 349-355.

Webster R. (1994) Gems: Their Sources, Descriptions and Identification, 5th ed. Rev. by P. G. Read, Butterworth-Heinemann, Oxford, UK, p. 375. 